\title{
Antihypertensive Drugs in the Elderly: Risks and Benefits as Evaluated by the FORTA Method
}

\section{Kuhn-Thiel AM and Wehling $M^{*}$}

Institute for Experimental and Clinical Pharmacology, Faculty of Medicine Mannheim, University of Heidelberg, 68169 Mannheim, Germany

*Corresponding author: Martin Wehling, Institute for Experimental and Clinical Pharmacology, Maybachstrasse, Mannheim, Germany, Tel: 49621383 9631; Fax: 49621383 9632; E-mail: martin.wehling@medma.uni-heidelberg.de

Rec date: Jul 28, 2014; Acc date: Aug 22, 2014; Pub date: Aug 25, 2014

Copyright: (c) 2014 Kuhn-Thiel AM, et al. This is an open-access article distributed under the terms of the Creative Commons Attribution License, which permits unrestricted use, distribution, and reproduction in any medium, provided the original author and source are credited.

\begin{abstract}
The management of polypharmacy in the elderly is a growing concern worldwide. Taking multiple medications can cause more harm than good, given that an estimated 100,000 medication-related deaths occur in the U.S. annually. Specific criteria were established by Beers (1997) for drugs to avoid in elderly patients. Although widely used, no clinical endpoints were improved, thus stressing the need for additional positive labeling of drugs as data on morbidity, mortality and safety become available for this patient collective. The FORTA (Fit fOR The Aged) method is the first approach combining positive and negative labeling of drugs. Class A drug is indispensable, B drugs have some restrictions, and $C$ drugs are critical and need careful balancing of desired/undesired effects. D drugs should generally be avoided. Commonly-used medications for major diseases, among them hypertension, were assigned these labels in the FORTA list according to evidence as to age-appropriateness by an expert panel in a Delphi Consensus Procedure. In hypertension, RAS-inhibitors and long-acting dihydropyridine calcium blockers are A drugs, diuretics and beta blockers $B$ drugs. This means that uncomplicated hypertension is preferentially treated by $A$ drugs, $B$ drugs are only given if $A$ drugs are exhausted. $C$ drugs represent second line compounds such as moxonidine or spironolactone which are difficult to use. The $D$ drugs clonidine or verapamil should be avoided in the elderly. Use of the FORTA list will support general practitioners struggling with polypharmacy with multiple diagnoses, as prioritization is possible not only for one disease, but also across therapeutic areas.
\end{abstract}

Keywords: Polypharmacy; Beers list; Hypertension treatment; Drug ranking

\section{Background}

As a consequence of the demographic revolution taking place in the industrialized countries, clinical approaches aimed at optimizing the care and management of our older members of society are developing equally rapidly. According to reports published by the U.S. Census Bureau in 2005, the portion of the population over 65 years of age is projected at $19.6 \%$ in the U.S. by the year 2030; for Germany, this figure is even higher, at $27.5 \%$ [1]. It is estimated that approximately 100,000 deaths/year occur in the U.S. from medication errors, nonerrors and adverse effects [2]. While alarming in and of itself, this takes on a greater dimension when it is considered that elders are more likely to take multiple drugs (polypharmacy) [3]. The pharmacotherapy of elderly patients may be impeded by factors such as a paucity of evidence available on specific substances as well as physiological alterations due to natural aging processes, complicated by polypharmacy, adverse events and drug-drug or drug-disease interactions [4]. Strict adherence to available guidelines may as a result be quite difficult and possibly even dangerous at times [5]. The lack of substantial literature concerning the optimal drug management of elderly patients with polypharmacy as well as the paucity of evidence generated by clinical studies [6], serve to stress the growing urgency of providing age-appropriate alternatives.

\section{Discussion}

\section{The FORTA method}

According to the National Institute for Health and Clinical Excellence (www.nice.org.uk: "Setting Standards for the Diagnosis and Treatment of Hypertension"), the pharmacotherapy of arterial hypertension represents "one of the most common interventions in primary care." Hypertension is a well-recognized risk factor for cardiovascular morbidity and mortality $[7,8]$. Raising awareness as to the options for optimizing the pharmacotherapy of hypertension appears to represent an essential component of overall improvement of patient outcome in the elderly. The FORTA method (=Fit fOR The Aged), created in Germany in 2008, has become increasingly popular within Germany and Austria [9], augmenting other available countryspecific listings created over the past few decades [10]. The system, based on ratings assigned to commonly prescribed medications, was designed to aid physicians in targeting overtreatment and undertreatment in their older patients. Here, the FORTA principle will be introduced and exemplified by the selected indication of arterial hypertension.

\section{Delphi expert consensus procedure 2012}

A two-round Delphi consensus procedure was performed in 2012 [11] in which 20 leading geriatric internists and geriatric psychiatrists from Germany and Austria reached a consensus concerning the choice of labels for the original 190 substances listed in the original book publication [12]. This survey led to the compilation of a revised list, 
Citation: Kuhn-Thiel AM, Wehling $\mathrm{M}^{*}$ (2014) Antihypertensive Drugs in the Elderly: Risks and Benefits as Evaluated by the FORTA Method. J

Page 2 of 3

with 230 substances ranked from A-B-C-D under 20 main diagnosis headings. The classes are defined as follows:

Class A (A-bsolutely) Indispensable drug, clear-cut benefit in terms of efficacy/safety ratio proven in elderly patients for a given indication

Class B (B-eneficial) Drugs with proven or obvious efficacy in the elderly, but limited extent of effect or safety concerns

Class C (C-areful) Drugs with questionable efficacy/safety profiles in the elderly which should be avoided or omitted in the presence of too many drugs or side effects

Class D (D-on't) Avoid in the elderly, omit first, refer also to negative listings (e.g. Beers list).

In the Delphi Expert Consensus Procedure 2012 [11], a consistently high consensus rate was achieved for the FORTA ratings for all 11 substances used to treat hypertension, thus corroborating the original authors' labels [12]. The categorization was evidence-based with the results of the systematic review compiled in ref. 12, but - as in many situations clear evidence is missing - supplemented by consensus ratings.
Risks and benefits of the 11 antihypertensive substance groups rated are summarized in Table 1. Three substances or substance groups received the A label; two received the $\mathrm{B}$ label; three were assigned the $\mathrm{C}$ label and three were assigned the D label. This not only reflects firstline or second-line therapy, but also allows a general ranking order for overall age-appropriateness of these substances. The "higher" categories do not necessarily strictly equate with actual drug safety, but rather reflect the strength of evidence for elderly persons in terms of adherence issues and benefit/risk considerations. Of course, the grouping of drugs without assessment of individual compounds may lead to over-simplification; e.g., indapamide as the thiazide successfully employed in the HYVET trial on hypertension treatment in the very elderly [13] could possibly be labeled A, as opposed to B for all other thiazides. The number of antihypertensive drugs to be escalated to treat hypertension effectively needs to be determined carefully in a step-up process; likewise, hypotension must be considered for reversal of this escalation [14].

\begin{tabular}{|c|c|c|c|}
\hline $\begin{array}{l}\text { Indication arterial Hypertension: } \\
\text { Substance/group }\end{array}$ & $\begin{array}{l}\text { FORTA Class } \\
\text { (original labels confirmed by expert } \\
\text { consensus) }\end{array}$ & Benefits & Risks \\
\hline $\begin{array}{l}\text { Renin-Angiotensin system inhibitors } \\
\text { ACE inhibitors }\end{array}$ & A & $\begin{array}{l}\text { Abundance of favorable data for } \\
\text { elderly; well-tolerated }\end{array}$ & \\
\hline Angiotensin receptor antagonists & A & $\begin{array}{l}\text { Abundance of favorable data for } \\
\text { elderly; well-tolerated }\end{array}$ & \\
\hline $\begin{array}{l}\text { Long-acting calcium antagonists, } \\
\text { dihydropyridine } \\
\text { type, for example amlodipine }\end{array}$ & A & Excellent sources of data for elderly & \\
\hline Betablockers & B & $\begin{array}{l}\text { Positive data, primarily from older } \\
\text { studies }\end{array}$ & $\begin{array}{l}\text { Not always well-tolerated due to } \\
\text { absolute or relative contraindications }\end{array}$ \\
\hline Diuretics & B & $\begin{array}{l}\text { Positive data available for thiazide } \\
\text { diuretics in very old }(>80 \text { years }) \\
\text { patients }\end{array}$ & $\begin{array}{l}\text { Insufficient data on loop diuretics; } \\
\text { studies show poor adherence; risk of } \\
\text { life-threatening conditions with } \\
\text { insufficient monitoring }\end{array}$ \\
\hline Alpha blockers & c & Second-line therapy & $\begin{array}{l}\text { Scarcity of data for elderly; risk of } \\
\text { adverse effects }\end{array}$ \\
\hline Spironolactone & c & $\begin{array}{l}\text { Second-line therapy in refractory } \\
\text { hypertension }\end{array}$ & $\begin{array}{l}\text { Risk of severe adverse effects } \\
\text { particularly in the elderly; }\end{array}$ \\
\hline Moxonidine & c & Second-line therapy & $\begin{array}{l}\text { Risk of adverse effects, particularly } \\
\text { hypotension }\end{array}$ \\
\hline Clonidine & $\mathrm{D}$ & & $\begin{array}{l}\text { Very poorly tolerated in the elderly. } \\
\text { Danger of delirium, syncope }\end{array}$ \\
\hline Minoxidil & $\mathrm{D}$ & & $\begin{array}{l}\text { Poorly tolerated: severe and } \\
\text { unpredictable adverse effects } \\
\text { common in elderly patients; } \\
\text { alternatives available }\end{array}$ \\
\hline Calcium antagonists, verapamil type & D & & $\begin{array}{l}\text { Life-threatening adverse effects; poor } \\
\text { tolerance in the elderly; alternatives } \\
\text { available }\end{array}$ \\
\hline
\end{tabular}

Table 1: FORTA ratings for antihypertensive drugs [12], corroborated by the 2012 Expert Consensus Procedure [11] 


\section{The FORTA method in theory and practice}

The FORTA method allows a quick assessment of antihypertensive substances in terms of both overtreatment and undertreatment. The latter may be viewed as equally advantageous, as even very old patients (>80 years) may well profit from antihypertensive drug therapy [13]. Indeed, many very helpful therapy options may have been unintentionally withheld [15]. FORTA's cross therapeutic prioritization feature additionally allows greater precision in terms of determining the age-appropriateness for substances with respect to many diagnoses at once, according to a standard, reproducible scheme. An alternative listing approach, START/STOP [16] could still lead to polypharmacy if several START-conditions are met, as it does not prioritize treatments across indications.

The positive options provided by FORTA for the treatment of arterial hypertension mark this disease as a favorably treatable one, indicating safer alternatives (FORTA A and B), compared to other diagnoses with less compelling options, for example, long-term treatment of psychiatric conditions, with a higher number of FORTA $\mathrm{C}$ and $\mathrm{D}$ ratings and lower number of safer and age-appropriate FORTA A and B alternatives [11,12].

\section{Summary}

The FORTA classification system sets a precedent by applying positive and negative ratings to medications commonly used in treating hypertension, among other indications, allowing a quick assessment of undertreatment as well as overtreatment. This ranking aspect would facilitate the identification of therapeutic "gaps" on the one hand (A or B options available, not prescribed), and redundancy or inappropriate treatment on the other (superfluous $\mathrm{A}$ and $\mathrm{B}$ medications prescribed; $\mathrm{C}$ and $\mathrm{D}$ medications prescribed when more age-appropriate alternatives are available; or substances prescribed with no clear indication). When used according to specific users' criteria, the FORTA system would thus be effective not only as a quick desktop aid, but also possibly as a standard component of team-based decision-making processes supporting particularly challenging therapeutic decisions (e.g. therapy-resistant hypertension).

\section{Competing Interests}

AK-T declares no competing interests.

MW was employed by AstraZeneca R\&D, Mölndal, as director of discovery medicine (=translational medicine) from 2003-2006, while on sabbatical leave from his professorship at the University of Heidelberg. Since returning to this position in January 2007, he has received lecturing and consulting fees from Sanofi-Aventis, Novartis, Takeda, Roche, Pfizer, Bristol-Myers, Daichii-Sankyo, Lilly, NovoNordisk, Shire and LEO Pharma.

\section{Author Contributions}

AK-T prepared and drafted the manuscript. MW oversaw all aspects of this process and made major contributions to the drafting of the manuscript.

\section{Ethics Statement}

No research on human subjects has been performed in connection with the concept as presented in this article. Likewise, no data, from patients or any other human subjects, have been collected or compiled for use in this paper. Therefore, no ethical statement has been obtained from the responsible ethics committee and authorities at the University of Heidelberg.

\section{Acknowledgments}

We would like to thank Christine Schummer for her excellent secretarial support.

\section{References}

1. Wan H, Sengupta M, Velkoff VA, DeBarros KA (2005) 65+ in the United States: 2005. U.S. Census Bureau, Current Population Reports, U.S. Government Printing Office: Washington.

2. Lazarou J, Pomeranz BH, Corey PN (1998) Incidence of adverse drug reactions in hospitalized patients: a meta-analysis of prospective studies. JAMA 279: 1200-1205.

3. Drenth-van Maanen AC, van Marum RJ, Knol W, van der Linden CM, Jansen PA (2009) Prescribing optimization method for improving prescribing in elderly patients receiving polypharmacy: results of application to case histories by general practitioners. Drugs Aging 26: 687-701.

4. Jansen PA, Brouwers JR (2012) Clinical pharmacology in old persons. Scientifica (Cairo) 2012: 723678.

5. Wehling M (2011) Guideline-driven polypharmacy in elderly, multimorbid patients is basically flawed; there are almost no guidelines for these patients. J Am Geriatr Soc 59: 376-377.

6. Gurwitz JH (2004) Polypharmacy: a new paradigm for quality drug therapy in the elderly? Arch Intern Med 164: 1957-1959.

7. Dawber TR, Kannel WB (1966) The Framingham study. An epidemiological approach to coronary heart disease. Circulation 34: 553-555.

8. Aronow WS (2013) Hypertension-related stroke prevention in the elderly. Curr Hypertens Rep 15: 582-589.

9. Levy HB, Marcus EL, Christen C (2010) Beyond the beers criteria: A comparative overview of explicit criteria. Ann Pharmacother 44: 1968-1975.

10. Wehling M (2008) [Drug therapy in the elderly: too much or too little, what to do? A new assessment system: fit for the aged (FORTA]. Dtsch Med Wochenschr 133: 2289-2291.

11. Kuhn-Thiel AM, Weiß C, Wehling M; FORTA authors/expert panel members (2014) Consensus validation of the FORTA (Fit fOR The Aged) List: a clinical tool for increasing the appropriateness of pharmacotherapy in the elderly. Drugs Aging 31: 131-140.

12. Wehling M (2013) Drug therapy for the Elderly. Vienna: Springer Publishers.

13. Beckett NS, Peters R, Fletcher AE, Staessen JA, Liu L, et al. (2008) Treatment of hypertension in patients 80 years of age or older. $\mathrm{N}$ Engl J Med 358: 1887-1898.

14. Schneider EL, Campese VM (2010) Adverse drug responses: An increasing threat to the well-being of older patients: Comment on "Development and validation of a score to assess risk of adverse drug reactions among in-hospital patients 65 years or older". Arch Intern Med 170: 1148-1149.

15. Steinman MA, Landefeld CS, Rosenthal GE, Berthenthal D, Sen S, et al. (2006) Polypharmacy and prescribing quality in older people. J Am Geriatr Soc 54: 1516-1523.

16. Gallagher P, Ryan C, Byrne S, Kennedy J, O'Mahony D (2008) STOPP (Screening Tool of Older Person's Prescriptions) and START (Screening Tool to Alert doctors to Right Treatment). Consensus validation. Int J Clin Pharmacol Ther 46: 72-83. 